\title{
Study on Numerical Solution of a Variable Order Fractional Differential Equation based on Symmetric Algorithm
}

(Kajian Penyelesaian Berangka Peringkat Berubah Persamaan Pembezaan Pecahan berdasarkan Algoritma Simetri)

\author{
JINGRUI LIU \& DONGYANG PAN*
}

\begin{abstract}
ABSTRAK
As the class of fractional differential equations with changing order has attracted more attention and attention in the fields of research and engineering, it is important to study its numerical solutions. Numerical solution algorithm for a class of fractional differential equations with transformed arrays based on the proposed symmetry algorithm. The symmetry classification is used for the class of values of the boundary problem of the fractional differential equation with the order of change. A fully symmetric classification of the boundary value problem for a class of fractional differential equations with variable sequences is determined by using a fully symmetric differential sequence sorting algorithm. The problem of the boundary value of the fractional differential equation with the transformed order is reduced to the initial value of the ordinary differential equation. The Legendre polynomial method is used to solve the numerical solution of the starting value of the differential equation. The common differential equation is transformed into a matrix series product by a different operator matrix. The matrix products are converted to algebraic equations by discrete variables. By solving the equations, the numerical solution of the starting value of the common differential equation is obtained.
\end{abstract}

Keywords: Boundary value problem; differential equation; numerical solution; operator matrix; symmetric algorithm; variable fractional order

\section{ABSTRAK}

Oleh kerana kelas persamaan pembezaan pecahan dengan susunan berubah telah menarik banyak perhatian dan perhatian dalam bidang penyelidikan dan kejuruteraan, ia amat penting untuk mengkaji penyelesaian berangkanya. Algoritma penyelesaian berangka untuk kelas persamaan pembezaan pecahan dengan transformasi tatasusunan berdasarkan algoritma simetri yang dicadangkan. Pengelasan simetri digunakan untuk nilai kelas masalah sempadan persamaan pembezaan pecahan dengan susunan berubah. Pengelasan simetrik sepenuhnya masalah nilai sempadan untuk kelas persamaan pembezaan pecahan dengan jujukan pemboleh ubah ditentukan dengan menggunakan algoritma pengisihan jujukan pembezaan simetrik sepenuhnya. Masalah nilai sempadan persamaan pembezaan pecahan dengan peringkat berubah dikurangkan kepada masalah nilai awal persamaan pembezaan biasa. Kaedah polinomial Legendre digunakan untuk menyelesaikan penyelesaian berangka masalah nilai permulaan persamaan pembezaan. Persamaan pembezaan biasa diubah menjadi produk siri matriks oleh pengendali matriks lain. Produk matriks ditukar kepada persamaan algebra oleh variat diskret. Dengan menyelesaikan persamaan, penyelesaian berangka nilai permulaan persamaan pembezaan biasa diperoleh.

Kata kunci: Algoritma simetri; masalah nilai sempadan; matriks pengendali; penyelesaian berangka; peringkat pecahan berubah; persamaan pembezaan

\section{INTRODUCTION}

Fractional calculus is a part of the theory of calculus of arbitrary real order (Bhrawy \& Zaky 2016). Fractional calculus equation refers to the equation containing noninteger derivatives. Its advantage is that this model can form a mathematical model with fewer parameters and describe the memory and inheritance of materials in a larger frequency range (Wang et al. 2017). However, classical integer differential equation is difficult to describe these properties. The computational theory of fractional calculus has not only become an academic hot topic in the field of mathematics, but also the research of fractional differential equations in various research fields, optical, thermal systems and rheology and materials as well as mechanical systems, signal processing and even It is the system knowledge and other industries that have carried out more in-depth exploration of this research (ZúñigaAguilar et al. 2017). The theory of fractional calculus has attracted more and more attention from scholars at home and abroad. Especially the fractional differential equation abstracted from practical problems has become a research hotspot for many mathematicians. In recent years, more first-line scholars have found that many variables in the dynamic process appear fractional order, which can change with time and space (Bhrawy \& Zaky 2015). More and more facts show that variable fractional order computation 
the mathematical system is constructed for the analysis of complex dynamics (Yu et al. 2016). The definition of variable order operator has been gradually developed in recent years, and its emergence has brought new paradigms in the field of fractional order research.

In 1873, Lie, a Norwegian mathematician, first put forward the symmetry theory of differential equations in order to unify and expand various methods of solving ordinary differential equations (Zhang et al.2017). The so-called symmetry refers to the continuous transformation group of single parameters acting on the Variable space so that differential equation does not change (Danca 2015). Symmetric classification is one of the challenging problems in symmetric algorithms. As a new application of Wu's method in differential field, Temur Chaolu proposed a fully symmetrical differential characteristic sequence algorithm for differential equation classification (Liu et al. 2015). The theory overcomes the shortcomings of traditional Lie algorithm, makes the determination and classification of symmetry more systematic and direct, thus expanding the application scope of symmetrical algorithm.

In this paper, a numerical solution algorithm for a class of fractional differential equations with variable order based on symmetric algorithm is proposed. A symmetric algorithm is used to calculate the Boundary Value Problem (hereinafter referred to as BVP) of non-variable fractional differential equations, so that the complete symmetric classification is determined. The reduced value of the classified boundary value is obtained to obtain the initial value of the ordinary differential equation, and the numerical solution of the initial value is obtained.

\section{NUMERICAL SOLUTION OF A CLASS OF FRACTIONAL DIFFERENTIAL EQUATION WITH VARIABLE ORDER BASED ON SYMMETRIC ALGORITHMS}

\section{DEFINITION OF VARIABLE ORDER FRACTIONAL CALCULUS}

Definition of Variable Fractional Integral of RiemannLiouville Type

$$
I_{t}^{\alpha(t)} u(t)=\frac{1}{\Gamma(\alpha(t))} \int_{0}^{t}(t-T)^{\alpha(t)-1} u(T) d T, \mathrm{~m}-1 \leq \alpha(t)<m
$$

Definition of Riemann-Liouville Type of Fractional Differential with Variable Order

$$
D_{\alpha+}^{\alpha(t)} u(t)=\frac{1}{\Gamma(m-\alpha(t))} \frac{d^{m}}{d t^{m}} \int_{a}^{t} \frac{u(\tau)}{(t-\tau)^{\alpha(t)-m+1}} d \tau, \mathrm{m}-1 \leq \alpha(t)<m
$$

where $t>0, m$ is a positive integer and $u(t)$ is a continuous differentiable function. If the $\alpha(t)=c$ (constant), then the definition becomes the definition of Riemann-Liouville type of fractional integral and reciprocal, which have properties for any differentiable function $u(t)$ :

$$
D_{\alpha+}^{\alpha(t)} I_{\alpha+}^{\alpha(t)} u \neq u
$$

Definition of Fractional Differential with Variable Order of Captuo Type

$D^{\alpha(t)} u(t)=\frac{1}{\Gamma(1-\alpha(t))} \int_{0+}^{t}(t-\tau)^{-\alpha(t)} \mathrm{u}^{\prime}(\tau) \mathrm{d} \tau+\frac{(u(0+)-u(0-)) t^{-\alpha(t)}}{\Gamma(1-\alpha(t))}$

where $0<\alpha(t) \leq 1$. If $\alpha(t)=c$ (constant), the definition edge becomes the Captuo definition of fractional reciprocal. If the initial conditions are good enough, the following definitions can be obtained:

$$
D^{\alpha(t)} u(t)=\frac{1}{\Gamma(1-\alpha(t))} \int_{0+}^{t}(t-\tau)^{-\alpha(t)} \mathrm{u}^{\prime}(\tau) \mathrm{d} \tau, 0<\alpha(t)<1
$$

The property is:

$$
\begin{aligned}
& D^{\alpha(t)} c=0 \\
& D_{\cdot}^{\alpha(t)} x^{\beta}=\left\{\begin{array}{lr}
0, & \beta=0 \\
\frac{\Gamma(\beta+1)}{\Gamma(\beta+1-\alpha(t))} x^{\beta-\alpha(t)}, \beta=1,2,3 \cdots
\end{array}\right.
\end{aligned}
$$

\section{SYMMETRIC CLASSIFICATION}

A fractional differential equation with variable order and parameter $\theta$ is referred to:

$$
\Delta(\theta ; x, u)=0
$$

whereas $x \in R^{n}(n \geq 1)$ is an independent variable and is a dependent variable, let $G_{\theta}$ be all the symmetries allowed by (8) when $\theta$ goes through its definition domain, which is called the global symmetry of (8). The problem of determining all parameters $\theta$ and the corresponding global matrix $G_{\theta}$ is called the symmetric classification problem of the fractional differential equation with variable order of the function. If the classification is exhaustive, it is called the complete symmetric classification problem (El-Sayed \& Agarwal 2019; Rossi \& Topp 2016). For all parameters $\theta$, the symmetry of (8) is called the principal symmetry of (8) (Bauer et al. 2015), which is denoted as $G_{\theta}$. Therefore, for a parameter value $\tilde{\theta}$, there is $G_{0} \subseteq G_{\theta}$ as a set of symmetric transformations. When there is $G_{\bar{\theta}}$ $\neq G_{0}$ for a parameter value $\theta=\tilde{\theta}$, we call $G_{\bar{\theta}}$ an extended symmetry of $G_{0}$.

The problem of symmetric classification not only has its theoretical significance, but also has strong practical significance. Many differential equations describing mathematical and physical problems contain parameters that are difficult to determine experimentally and experientially. However, practical problems require that the solutions of these parameters and equations be determined 
under certain conditions, such as symmetry. Generally, these parameters appear in tables and graphics (Baeumer et al. 2015). They play the role of arbitrary parameters in the continuous equation describing the problem, so when solving BVP of a class of fractional differential equation with variable order by using symmetric classification algorithm, it can determine different symmetries according to different parameters, and use these symmetries to make different reductions to the studied BVP.

\section{APPLICATION OF SYMMETRIC CLASSIFICATION TO BVP OF A CLASS OF FRACTIONAL DIFFERENTIAL EQUATION WITH VARIABLE ORDER}

The governing equation considering the BVP is:

$$
\begin{aligned}
& u_{x}+v_{y}=0 \\
& u u_{x}+v u_{y}=u_{y y}+S(x) w \\
& u\left[w_{x}+w \frac{d \ln (S(x))}{d x}\right]+v w_{y}=\frac{1}{\operatorname{Pr}} w_{y y}
\end{aligned}
$$

The boundary adjustment is as follows:

$$
\begin{aligned}
& v(x, 0)=B_{1}(x), u(x, 0)=B_{1}(x), \\
& u(x, 0)=B_{3}(x), u(x, \infty)=0 \\
& w(x, 0)=B_{4}(x), w_{y}(x, 0)=B_{5}(x), w(x, \infty)=0
\end{aligned}
$$

where the function $B_{i}(x)(i=1,2,3,4,5)$ is then determined by the invariance of the boundary conditions under symmetry (Shao \& Chen 2015).

Firstly, it needs to define a stream function $\psi$ :

$$
u=\psi_{y}, v=-\psi_{x}
$$

Then, (9) satisfies naturally, therefore, the governing equation can be written as follows:

$$
\begin{aligned}
& \psi_{y} \psi_{x y}-\psi_{x} \psi_{y y}=\psi_{y y y}+S(x) w \\
& \psi_{y}\left[w_{x}+w \frac{d \ln (S(x))}{d x}\right]-\psi_{x} w_{y}=\frac{1}{\operatorname{Pr}} w_{y y}
\end{aligned}
$$

The corresponding boundary conditions become:

$$
\begin{aligned}
& \psi_{x}(x, 0)=-B_{1}(x), \psi_{y}(x, 0)=\beta_{2}(x), \\
& \psi_{y y}(x, 0)=B_{3}(x), \psi_{y}(x, \infty)=0 \\
& w(x, 0)=B_{4}(x), w_{y}(x, 0)=B_{5}(x), w(x, \infty)=0
\end{aligned}
$$

Fully Symmetric Classification of BVP for Determining Fractional Differential Equation with Variable Order

Assuming that the infinitesimal vectors corresponding to the symmetry of fractional differential (15) and (16) with variable order are:

$$
\begin{array}{r}
X=\xi(x, y, \psi, w) \frac{\partial}{\partial x}+\tau(x, y, \psi, w) \frac{\partial}{\partial y}+ \\
\eta(x, y, \psi, w) \frac{\partial}{\partial \psi}+\varphi(x, y, \psi, w) \frac{\partial}{\partial w}
\end{array}
$$

where, $\xi(x, y, \psi w), \tau(x, y, \psi, w), \eta(x, y, \psi, w)$ and $\varphi(x, y$, $\psi, w)$ are called infinitesimal generating functions of the symmetry.

Generation of Deterministic Equation with Parameter $S(x)$

According to LIE algorithm, the symmetrical deterministic (15) and (16) can be obtained by using the arithmetic of generating deterministic equations, that is, the system DPS composed of $D P S=0$ of differential polynomial system:

$D P S=\left\{\begin{array}{l}\xi_{y}, \xi_{\psi}, \xi_{w}, \tau_{y y}, \tau_{x y}, \tau_{\psi}, \tau_{w}, \eta_{x}, \eta_{y}, \eta_{\psi \psi}, \eta_{w}, \varphi_{y}, \varphi_{\psi}, \varphi_{w w} \\ \eta_{\psi}-\xi_{x}+\tau_{y}, \varphi_{w}-2 \tau_{y},\left(w \eta_{\psi}-\varphi-3 w \tau_{y}\right) S(x)-w \xi S^{\prime}(x) \\ \varphi_{x} S^{2}(x)+\left(\varphi+w \eta_{\psi}-w \tau_{y}\right) S(x) S^{\prime}(x)-w \xi S^{\prime 2}(x)+w \xi S(x) S^{\prime \prime}(x)\end{array}\right\}=0$

\section{Determination of the Principal Symmetry}

If $S(x)$ is an arbitrary function, the deterministic system $D P S=0$ is further decomposed into $D P S_{0}=0$, where:

$$
D C S_{0}=\left\{\begin{array}{l}
\xi, \tau_{y y}, \tau_{x y}, \tau_{\psi}, \tau_{w}, \eta_{x}, \eta_{y}, \eta_{\psi \psi}, \eta_{w}, \varphi_{x}, \varphi_{y}, \varphi_{\psi}, \varphi_{w w} \\
\eta_{\psi}+\tau_{y}, \varphi_{w}-2 \tau_{y}, w \eta_{\psi}-\varphi-3 w \tau_{y}, \varphi+w \eta_{\psi}-w \tau_{y}
\end{array}\right\}=0
$$

By solving the system of (21), it can get zero set $\left(D C S_{0}\right)$, that is to say, the principal symmetric infinitesimal generating function.

$$
\xi=0, \tau=\tau(x), \eta=c, \varphi=0
$$

where $c$ is an arbitrary constant and $\tau(x)$ is an arbitrary function of $x$. By introducing (22) into (19), the principal symmetry is obtained.

$$
X_{0}=\tau(x) \frac{\partial}{\partial y}+c \frac{\partial}{\partial \psi}
$$

\section{Determination of Extended Symmetry}

Under the basic order $x$ p y p $\psi \mathrm{p} w$, the following zero decomposition is obtained according to the differential characteristic set algorithm of fully symmetric classification for determining the differential equations with parameters.

$$
z \operatorname{ero}(D P S)=\operatorname{zero}\left(D C S_{1} / I\right) \mathrm{U} \operatorname{zero}\left(D C S_{2}, I\right)
$$


where:

$$
\begin{aligned}
& D C S_{1}=\left\{\eta_{w}, \eta_{\psi}, \eta_{y}, \eta_{x}, \varphi, \xi, \tau_{w}, \tau_{\psi}, \tau_{y}\right\}, \\
& D C S_{2}=\left\{\eta_{w}, \eta_{y}, \eta_{x}, \xi_{w}, \xi_{\psi}, \xi_{y}, \tau_{w}, \tau_{\psi}, 6 \tau_{y} S^{\prime}(x)+\xi S^{\prime \prime}(x), \xi_{x} S(x) S^{\prime}(x)\right. \\
& -\xi S^{\prime 2}(x)+\xi S(x) S^{\prime \prime}(x),-6 \eta_{\psi} S(x) S^{\prime}(x)-6 \xi S^{\prime 2}(x) \\
& \left.+5 \xi S(x) S^{\prime \prime}(x), 3 \varphi S^{\prime}(x)+w \xi S^{\prime \prime}(x)\right\} \\
& I=S^{\prime 2}(x) S^{\prime \prime}(x)-2 S(x) S^{\prime \prime 2}(x)+S(x) S^{\prime}(x) S^{(3)}(x)
\end{aligned}
$$

It can easily get zero $\left(D C S_{0}\right)=z \operatorname{ero}\left(D C S_{1} / I\right)$. By solving the classification equation $I=0$, it can get:

$$
\operatorname{zero}(I)=\left\{S(x)=e^{x}, x^{n}(n \neq 0)\right\}
$$

The feature column set corresponding to parameter $S(x)$ is shown in Table 1 .

TABLE 1. Characteristic set

\begin{tabular}{cc}
\hline $\mathrm{S}(\mathrm{x})$ & Characteristic set \\
\hline $\mathrm{e}^{\mathrm{x}}$ & $\mathrm{DCS}_{2}$ \\
$\mathrm{x}^{\mathrm{n}}$ & $\mathrm{DCS}_{2}$ \\
\hline
\end{tabular}

Therefore, according to the different parameters of $S(x)$, zero $\left(D C S_{2}, I\right)$ is solved and the following classification results are obtained (Cozzi \& Passalacqua 2016):

When $S(x)=e^{x}$, there is

$$
X_{1}=a \frac{\partial}{\partial x}+\left[f(x)-\frac{\partial y}{6}\right] \frac{\partial}{\partial y}+\left(\frac{a \psi}{6}+b\right) \frac{\partial}{\partial \psi}-\frac{a w}{3} \frac{\partial}{\partial w}
$$

When $S(x)=x^{n}, n \neq 0$, there are

$X_{2}=a x \frac{\partial}{\partial x}+\left[f(x)+\frac{a y}{6}(1-n)\right] \frac{\partial}{\partial y}+\left(\frac{a \psi}{6}(5+n)+b\right) \frac{\partial}{\partial \psi}+\frac{a w}{3}(1-n) \frac{\partial}{\partial w}$

where $a$ and $b$ are arbitrary constants and $f(x)$ is arbitrary function. The final classification results are shown in Table 2.

TABLE 2. Infinitesimal vector

\begin{tabular}{cc}
\hline$S(x)$ & Infinitesimal vector \\
\hline$\forall$ & $\tau(x) \frac{\partial}{\partial y}+c \frac{\partial}{\partial \psi}$ \\
$\mathrm{e}^{\mathrm{x}}$ & $a \frac{\partial}{\partial x}+\left[f(x)-\frac{a y}{6}\right] \frac{\partial}{\partial y}+\left(\frac{a \psi}{6}+b\right) \frac{\partial}{\partial \psi}-\frac{a w}{3} \frac{\partial}{\partial w}$ \\
$\mathrm{X}^{\mathrm{n}}$ & $a x \frac{\partial}{\partial x}+\left[f(x)+\frac{a y}{6}(1-n)\right] \frac{\partial}{\partial y}+\left(\frac{a \psi}{6}(5+n)+b\right) \frac{\partial}{\partial \psi}-\frac{a w}{3}(1-n) \frac{\partial}{\partial w},(n \neq 0)$
\end{tabular}

\section{Reduced BVP}

The first extended symmetry (26) is used to reduce the BVP (15) - (18). The characteristic equation of symmetry (26) is:

$$
\frac{d x}{a}=\frac{d y}{f(x)-\frac{a y}{6}}=\frac{d \psi}{\frac{a \psi}{6}+b}=\frac{d w}{-\frac{a w}{3}}
$$

Invariants can be obtained from the equation $\frac{d x}{a}=\frac{d y}{f(x)-\frac{a y}{6}}$ :

$$
\xi=y e^{\frac{x}{6}}+F(x)
$$

where $F(x)$ is a function expressed by $f(x)$. The same principle can be obtained from the characteristic equation:

$$
\psi=-\frac{6 b}{a}+e^{\frac{x}{6}} s(\xi), w=e^{-\frac{x}{3}} g(\xi)
$$

By introducing (30) into (15) and (16), ordinary differential equation can be obtained.

$$
\left\{\begin{array}{l}
6 g-2 s^{\prime 2}+s s^{\prime \prime}+6 s^{\prime \prime \prime}=0 \\
4 g s^{\prime}-s g^{\prime}-\frac{6}{\mathrm{Pr}} g^{\prime \prime}=0
\end{array}\right.
$$

According to the invariance theorem of BVP for fractional differential equations with variable order, it can be seen that (Harko \& Liang 2016), boundary condition (17) and (18) are invariant under the extension of symmetry (26). Therefore, there are:

$$
X_{1}^{(1)}\left[\psi_{x}(x, y)+B_{1}(x)\right]=0, \text { when } \psi_{x}(x, 0)=-B_{1}(x)
$$

$$
\begin{aligned}
& X_{1}^{(1)}\left[\psi_{y}(x, y)+B_{2}(x)\right]=0 \text {, when } \psi_{y}(x, 0) \\
& =B_{2}(x), X_{1}^{(2)}\left[\psi_{y y}(x, y)-B_{3}(x)\right]=0 \text {, when } \psi_{y y}(x, 0)=B_{3}(x)
\end{aligned}
$$

$$
\begin{aligned}
& X_{1}\left[w(x, y)-B_{4}(x)\right]=0, \\
& \text { when } w(x, 0)=B_{4}(x), X_{1}^{(1)}\left[w_{y}(x, y)-B_{5}(x)\right]=0, \\
& \text { when } w_{y}(x, 0)=B_{5}(x), X_{1}^{(1)}\left[\psi_{y}(x, y)\right]=0, \\
& \text { when } \psi_{y}(x, \infty)=0 ; \\
& X_{1}[w(x, y)]=0, \text { 当 } w(x, \infty)=0 ;
\end{aligned}
$$

where $X_{1}^{(1)}$ and $X_{1}^{(2)}$ are infinitesimal vectors of the first and second order continuations of symmetric $X_{1}$, respectively, and can be deduced from the invariance theorem of BVP for fractional differential equation with variable order:

$$
X_{1}^{(1)}=X_{1}+\frac{a}{6} \psi_{x} \frac{\partial}{\partial \psi_{x}}+\frac{a}{3} \psi_{y} \frac{\partial}{\partial \psi_{y}}-\frac{a}{3} w_{x} \frac{\partial}{\partial w_{x}}-\frac{a}{6} w_{y} \frac{\partial}{\partial w_{y}}
$$




$$
\begin{aligned}
X_{1}^{(2)}= & X_{1}^{(1)}+\frac{a}{6} \psi_{x x} \frac{\partial}{\partial \psi_{x x}}+\frac{a}{3} \psi_{x y} \frac{\partial}{\partial \psi_{x y}}+\frac{a}{3} \psi_{x y} \frac{\partial}{\partial \psi_{y x}}+ \\
& \frac{a}{2} \psi_{y y} \frac{\partial}{\partial \psi_{y y}}-\frac{a}{3} w_{x x} \frac{\partial}{\partial w_{x x}}-\frac{a}{6} w_{x y} \frac{\partial}{\partial w_{x y}} \frac{a}{6} w_{x y} \frac{\partial}{\partial w_{y x}}
\end{aligned}
$$

$\frac{\partial}{\partial w_{y y}}$ does not appear because $\eta_{22}^{(2) w}=0$ is in the expression of second-order continuation $X_{1}^{(2)}$ (Pan et al. 2017). Thus, the functions $B_{1}(x), B_{2}(x), B_{3}(x), B_{4}(x)$ and $B_{5}(x)$ can be determined by the relation (32) - (34), that is:

$$
\begin{aligned}
& B_{1}(x)=b_{1} e^{\frac{x}{6}}, B_{2}(x)=b_{2} e^{\frac{x}{3}}, B_{3}(x)=b_{3} e^{\frac{x}{2}}, \\
& B_{4}(x)=b_{4} e^{-\frac{x}{3}}, B_{5}(x)=b_{5} e^{-\frac{x}{6}}
\end{aligned}
$$

where $b_{1}, b_{2}, b_{3}, b_{4}$ and $b_{5}$ are arbitrary constants.

In order to take $F(x)=0$ for corresponding boundary condition (17), (18), there are:

$$
\text { When } y=0, \xi=0 \text {; when } y \rightarrow \infty, \xi \rightarrow \infty
$$

According to the boundary conditions (17), (18) and the relation (30), the initial conditions are obtained.

$$
\begin{aligned}
& s(0)=-6 b_{1}, s^{\prime}(0)=b_{2}, s^{\prime \prime}(0)=b_{3}, g(0)=b_{3}, \\
& g(0)=b_{4}, g^{\prime}(0)=b_{5}, s^{\prime}(\infty)=0, g(\infty)=0
\end{aligned}
$$

LEGENDRE POLYNOMIAL METHOD FOR SOLVING INITIAL VALUE PROBLEMS OF A CLASS OF FRACTIONAL DIFFERENTIAL EQUATION WITH VARIABLE ORDER

Definition and Properties of Legendre Polynomials

Definition 1 The Legendre polynomial defined on $[0,1]$ is:

$$
P_{i+1}(t)=\frac{(2 i+1)(2 t-1)}{(i+1)} P_{i}(t)-\frac{i}{i-1} P_{i-1}(t), i=1,2, \cdots
$$

where $P_{0}(t)=1, P_{1}(t)=2 t-1$, the analytical form of Legendre polynomial $P_{i}(t)$ of order $i$ can be expressed as:

$$
P_{i}(t)=\sum_{k=0}^{i}(-1)^{i+k} \frac{(i+k) !}{(i-k) !} \frac{t^{k}}{(k !)^{2}}
$$

Define:

$$
\Phi(t)=\left[P_{0}(t), P_{1}(t), \mathrm{L}, P_{n}(t)\right]^{T}
$$

Then $\Phi(t)$ can be expressed as follows:

$$
\Phi(t)=A T_{n}(t)
$$

$$
A=\left[\begin{array}{ccccc}
1 & 0 & 0 & \cdots & 0 \\
-1 & (-1)^{2} 2 ! & 0 & \cdots & 0 \\
(-1)^{2} & (-1)^{3} \frac{3 !}{1 !} & (-1)^{4} \frac{4 !}{2 !} & \cdots & 0 \\
\vdots & \vdots & \vdots & \vdots & \vdots \\
(-1)^{n} & (-1)^{n+1} \frac{(n+1) !}{(n-1) !} & (-1)^{n+1} \frac{(n+2) !}{(n-1) ! 2 !} & \cdots(-1)^{2 n} \frac{(2 n) !}{n !}
\end{array}\right], T_{n}(t)=\left[\begin{array}{c}
1 \\
t \\
\vdots \\
t^{n}
\end{array}\right]
$$

$A^{-1}$ is reversible, therefore:

$$
T_{n}(t)=A^{-1} \Phi(t)
$$

The square integrable function $f(t)$ defined on interval $[0,1]$ can be expanded by Legendre polynomial, usually only the first $n+1$ term is considered:

$$
f(t) \cong \sum_{i=0}^{n} c_{i} P_{i}(t)=c^{T} \Phi(t)
$$

The coefficient is $c=\left[c_{0}, c_{1}, \mathrm{~L}, c_{n}\right]^{T}$, and the coefficient can be determined by inner product (Carrillo et al. 2015), that is:

$$
c=Q^{-1}(f, \Phi(t))
$$

where $Q$ is a matrix of $(n+1) \times(n+1)$ orders. $Q$ is called the inner product matrix of $\Phi(t)$, and $Q$ can be calculated by the following equation:

$$
\begin{aligned}
& Q=\int_{0}^{1} \Phi(t) \Phi^{T}(t) d x=\int_{0}^{1}\left(A T_{n}(t)\right)^{T} \\
& d t=A\left(\int_{0}^{1} T_{n}(t) T_{n}^{T}(t) d t\right) A^{T}=A H A^{T}
\end{aligned}
$$

where $H$ is a Hilbert matrix, that is:

$$
H=\left[\begin{array}{cccc}
1 & \frac{1}{2} & \cdots & \frac{1}{n+1} \\
\frac{1}{2} & \frac{1}{3} & \cdots & \frac{1}{n+2} \\
\vdots & \vdots & \ddots & \vdots \\
\frac{1}{n+1} & \frac{1}{n+2} & \cdots & \frac{1}{2 n+1}
\end{array}\right]
$$

For the second-order function $u(x, t) \in L^{2}([0,1] \times[0,1])$, the Legendre polynomial approximation is still used.

$$
u(x, t) \cong \sum_{i=0}^{n} \sum_{j=0}^{n} u_{i j} P_{i}(x) P_{j}(t)=\Phi^{T}(x) U \Phi(t)
$$

where

where 


$$
U=\left[\begin{array}{cccc}
u_{00} & u_{01} & \cdots & u_{0 n} \\
u_{10} & u_{11} & \cdots & u_{1 n} \\
\vdots & \vdots & \ddots & \vdots \\
u_{n 0} & u_{n 1} & \cdots & u_{n n}
\end{array}\right]
$$

$U$ can be determined by the inner product, i.e.

$$
U=Q^{-1}(\Phi(x),(\Phi(t), u(x, t))) Q^{-1}
$$

Operator Matrix of Legendre Polynomial

Let $u(t)=c_{1}^{T} \Phi(t)$, the first derivative of can be obtained as follows:

$$
\Phi^{\prime}(t)=D \Phi(t)
$$

where $D$ is the $(n+1) \times(n+1)$ - order matrix, which is called the first-order differential operator matrix of Legendre polynomial. It can be obtained from (46):

$$
\Phi^{\prime}(t)=A\left[\begin{array}{l}
0 \\
1 \\
\vdots \\
n t^{n-1}
\end{array}\right]
$$

The following forms of $(n+1) \times n$-order matrix $V_{(n+1) \times n}$ and $n \times 1$-dimensional vector $T_{n}^{*}(t)$ are defined as:

$$
V_{(n+1) \times n}=\left[\begin{array}{cccc}
0 & 0 & 0 & 0 \\
1 & 0 & \cdots & 0 \\
0 & 2 & \cdots & 0 \\
\vdots & \vdots & \ddots & \vdots \\
0 & 0 & \cdots & n
\end{array}\right]
$$

By expanding $T_{n}^{*}(t)$ in the form of $\Phi(t)$, it can get:

$$
T_{n}^{*}(t)=B^{*} \Phi(t)
$$

where

$$
B^{*}=\left[\begin{array}{lll}
A_{[1]}^{-1} & A_{[2]}^{-1} & \cdots
\end{array} A_{[n]}^{-1}\right]^{T}
$$

Here $A_{[k]}^{-1}$ represents the $k$ th row of $A^{-1}$, therefore:

$$
\Phi^{\prime}(t)=A V_{(n+1) \times n} B^{*} \Phi(t)
$$

In this way, the first order differential operator matrix of Legendre polynomials can be expressed as:

$$
D=A V_{(n+1) \times n} B^{*}
$$

Therefore, we can get

$$
u^{\prime}(t)=c_{1}^{T} A V_{(n+1) \times n} B^{*} \Phi(t)
$$

According to Captuo definition and properties of fractional derivatives, it can get:

$$
\begin{aligned}
& D^{\beta(l)} u(t)=D^{\beta(t)} c^{T} \Phi(t)=c_{1}^{T} D^{\beta(t)} \Phi(t)=c_{1}^{T} D^{\beta(t)} A T_{n}(t) \\
& =c_{1}^{T} A D^{\beta(t)}\left[\begin{array}{c}
1 \\
t \\
\vdots \\
t^{n}
\end{array}\right]=c_{1}^{T} A\left[\begin{array}{c}
0 \\
\frac{\Gamma(2)}{\Gamma(2-\beta(t))} x^{-\beta(t)} \\
\frac{\Gamma(3)}{\Gamma(3-\beta(t))} x^{2-\beta(t)} \\
\vdots \\
\frac{\Gamma(n+1)}{\Gamma(n+1-\beta(t))} x^{n-\beta(t)}
\end{array}\right]
\end{aligned}
$$

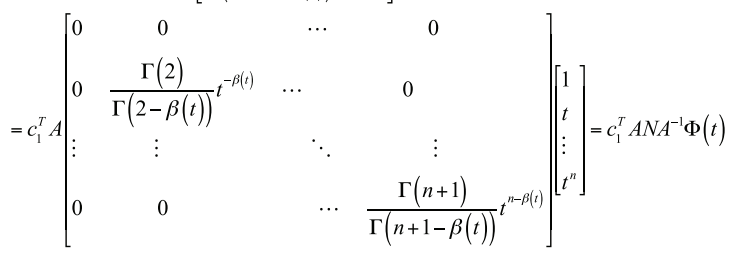

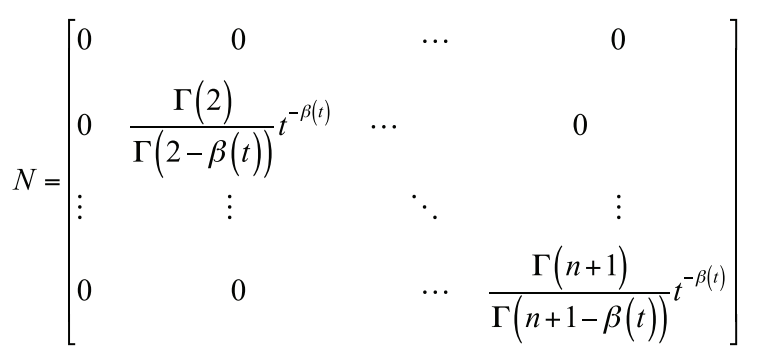

$\mathrm{N}$ is called the fractional differential operator matrix of Legendre polynomials. Therefore, there are:

$$
D^{\beta(t)} u(t)=c_{1}^{T} A N A^{-1} \Phi(t)
$$

Let $g(t)=c_{2}^{T} \Phi(t)$, and $c_{2}$ be calculated by (50). By using Caputo definition (Zhang et al. 2015) of variable order differential, it can get:

$$
\begin{aligned}
& D^{\alpha(t)}(u(t) g(t))=D^{\alpha(t)}\left(c_{1}^{T} \Phi g(t) \Phi^{T}(t) c_{2}\right)=D^{\alpha(t)}\left(c_{1}^{T} A T_{n}^{*}(t)\left(A T_{n}^{*}(t)\right)^{T} c_{2}\right) \\
& =D^{\alpha(t)}\left(c_{1}^{T} A T_{n}^{*}(t) T_{n}^{* T}(t) A^{T} c_{2}\right)=c_{1}^{T} A D^{\alpha(t)}\left(T_{n}^{*}(t) T_{n}^{* T}(t)\right) A^{T} c_{2}
\end{aligned}
$$

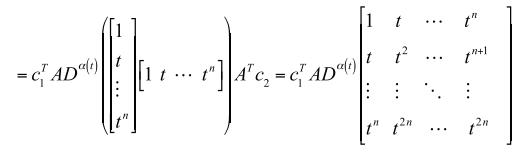

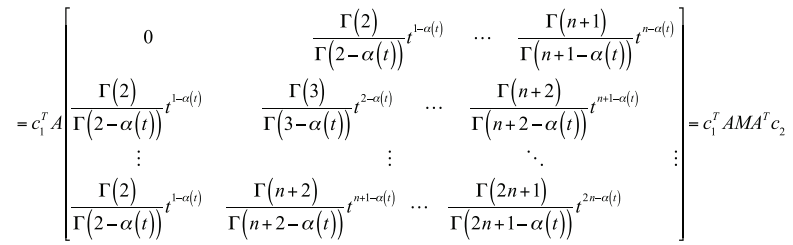




$$
M=\left[\begin{array}{cccc}
0 & \frac{\Gamma(2)}{\Gamma(2-\alpha(t))} t^{1-\alpha(t)} & \cdots & \frac{\Gamma(n+1)}{\Gamma(n+1-\alpha(t))} t^{t^{n-\alpha(t)}} \\
\frac{\Gamma(2)}{\Gamma(2-\alpha(t))} t^{1-\alpha(t)} & \frac{\Gamma(3)}{\Gamma(3-\alpha(t))} t^{t^{2-\alpha(t)}} & \cdots & \left.\frac{\Gamma(n+2)}{\Gamma(n+2-\alpha(t))}\right)^{n+1-\alpha(t)} \\
\vdots & \vdots & & \ddots \\
\left.\frac{\Gamma(n+1)}{\Gamma(n+1-\alpha(t))}\right)^{t^{n-\alpha(t)}} & \left.\frac{\Gamma(n+2)}{\Gamma(n+2-\alpha(t))}\right)^{n+1-\alpha(t)} & \cdots & \frac{\Gamma(2 n+1)}{\Gamma(2 n+1-\alpha(t))} t^{2 n-\alpha(t)}
\end{array}\right]
$$

$M$ is called fractional operator matrix of $D^{\alpha(t)}(u(t) g(t))$ part, therefore, it can be obtained:

$$
D^{\alpha(t)}(u(t) g(t))=c_{1}^{T} A M A^{T} c_{2}
$$

Equations (61), (64), (67) are introduced drag-in the initial equation, in the original equation can be transformed into:

$$
c_{1}^{T} A M A^{T} c_{2}+c_{1}^{T} A N A^{-1} \Phi(t)+c_{1}^{T} A V_{(n+1) \times n} B^{*} \Phi(t)=f(t)
$$

The unknown coefficient $c_{1}$ can be obtained by discrete variable $t$, and then the approximate numerical solution of the initial value problem for a class of fractional differential equation with variable order can be obtained.

$$
u(t)=c_{1}^{T} \Phi(t)
$$

\section{RESULTS}

In order to verify the performance advantages of the proposed numerical solution algorithm for a class of fractional differential equation with variable order based on symmetric algorithm, the experiment is carried out to solve the variable order fractional differential equation $D^{\frac{t}{4}}\left(u^{2}(t)\right)+D^{\frac{t}{3}} u(t)+u^{\prime}(t)=f(t) \quad u(0)=0, t \in[0,1]$. $f(t)=2 t+\frac{18 t^{2-t / 3}}{\left(18-9 t+t^{2}\right) \Gamma(1-t / 3)}+\frac{6144 t^{4-t / 4}}{(-16+t)(-12+t)(-8+t)(-4+t) \Gamma(1-t / 4)}$ is taken. Exact solution is $u(t)=t$. When $n=2$ is taken, the discrete variable $t_{i}=\frac{k_{i}}{2}-\frac{1}{4}, k_{i}=1,2$ right ), and $c_{1}=$ $\left[0-1.25 \times 10^{-16} 1\right]^{T}$ is obtained. Therefore, the numerical solution is $u(t)=C_{1}^{T} \Phi(t)$, where $\Phi(t)=\left[(1-t)^{2}(1-t) t t^{2}\right]^{T}$, and the algebraic expression of the numerical solution is $u(t)=-1.25 \times 10^{-16}(1-t) t+t^{2}$. Absolute errors between numerical solutions and exact solutions are obtained when $n=2, n=3$ and $n=4$, respectively, in Figures $1-3$.

Analysis of Figures $1-3$ show that when $n$ is 2, 3, and 4 , respectively, the numerical solution obtained by the proposed algorithm is basically consistent with the exact solution. It is shown that the algorithm presented in this paper is very effective in solving numerical solutions of fractional differential equation with variable order. At the same time, the algorithm is compared with the numerical solution algorithm of a class of fractional differential equation with variable order based on wavelet method and a class of fractional differential equation with variable order based on non-linear term variable sign. The accuracy

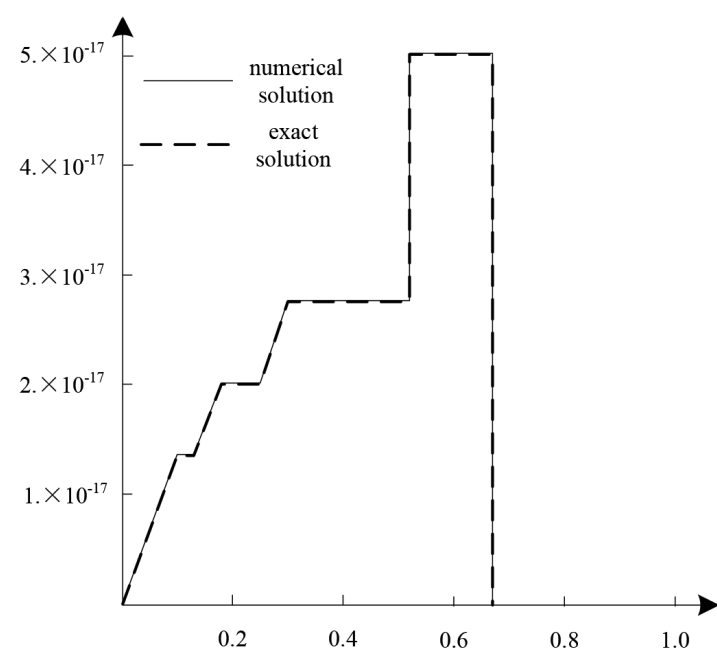

FIGURE 1. Absolute error between numerical solution and exact solution when $n=2$

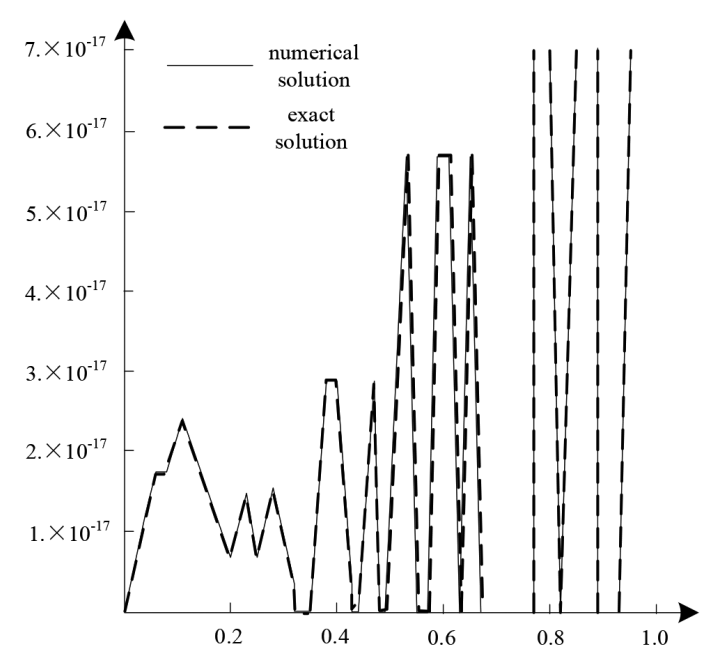

FIGURE 2. Absolute error between numerical solution and exact solution when $n=3$

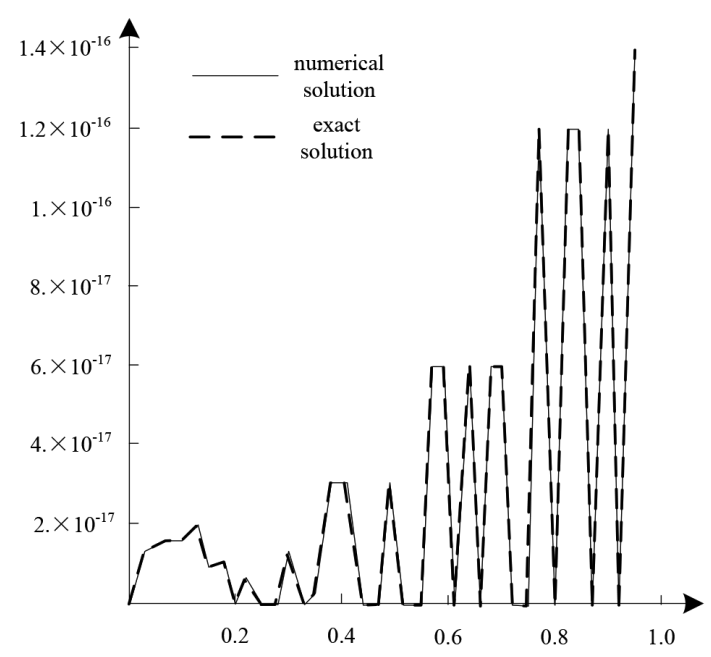

FIGURE 3. Absolute error between numerical solution and exact solution when $n=3$ 
TABLE 3. Accuracy comparison results of different algorithms

\begin{tabular}{cccc}
\hline \multicolumn{4}{c}{ An algorithm for solving a class of fractional differential equations with } \\
variable order based on wavelet method \\
\hline X position & $\begin{array}{c}\text { Numerical } \\
\text { solution }\end{array}$ & Exact solution & Error \\
\hline 2.4 & 0.80430000 & 0.80339167 & 0.00090833 \\
4.8 & 1.83840001 & 1.83575041 & 0.00264960 \\
6.4 & 1.63413334 & 1.63079520 & 0.00333814 \\
7.2 & 1.03410000 & 1.03101940 & 0.00308060 \\
\hline A numerical solution algorithm for a class of fractional differential equations \\
with variable order based on non-linear term variable sign \\
\hline \multicolumn{5}{c}{ Numerical } & Exact solution & Error \\
\hline \multicolumn{5}{c}{ solution } \\
\hline 0.4000 & 3.84011251 & 3.84000000 & 0.00011251 \\
0.5000 & 5.00012981 & 5.00000000 & 0.00012981 \\
0.6000 & 5.76013595 & 5.76000000 & 0.00013595 \\
0.7000 & 5.88012705 & 5.88000000 & 0.00012705 \\
\hline \multicolumn{5}{c}{ Text algorithm } \\
\hline \multicolumn{5}{c}{ X position } & Numerical & Exact solution & Error \\
\hline 0.3333 & 2.96319736 & 2.96316224 & 0.00003512 \\
0.5000 & 5.00028449 & 5.00020000 & 0.00008449 \\
0.7500 & 5.62520916 & 5.62520000 & 0.00000916 \\
0.8330 & 4.62977787 & 4.62972963 & 0.00004824 \\
\hline
\end{tabular}

of different algorithms is compared and the results are shown in Table 3.

As can be seen from Table 3 , the mean count value error obtained by the proposed algorithm is 0.00004425 .25 , the mean count value error obtained by the algorithm based on wavelet method is 0.002494168 , and the mean count value error obtained by the algorithm based on non-linear term variable is 0.00012633 . The mean count value error obtained by the proposed algorithm is significantly lower than that of the other two algorithms. It can be seen that the mean count value error obtained by the proposed algorithm is lower than that of the other two algorithms. The accuracy of the solution is higher than that of other algorithms.

\section{DISCUSSION}

In the previous section, the numerical solution's accuracy of a class of fractional differential equations with variable order is obtained by using the proposed algorithm. The experimental results show that the mean count value error of the numerical solution obtained by the proposed algorithm is lower than that of the comparative algorithms by 0.002405663 and 0.00008208 , respectively. The main reason for the high accuracy of this algorithm is that the symmetric algorithm is applied to a class of boundary value study of fractional differential equation with variable order. The complete symmetric classification for BVP of a given class of fractional differential equation and variable order is determined by using the differential characteristic sequence algorithm of fully symmetric classification of differential equation. By using an extended symmetry, the BVP of a class of fractional differential equation with variable order is reduced to the initial value problem of ordinary differential equation, which improves the accuracy of numerical solution.

\section{CONCLUSION}

In this paper, the application of differential equation and symmetric classification in solving boundary value numerical solutions of a class of differential equation with fractional order is studied. Firstly, a fully symmetric classification of boundary value count of fractional differential equation with parameters is analyzed and determined by using the differential characteristic sequence algorithm of fully symmetric classification of differential equation, and the equation is classified according to the different values of equation parameter $S[x]$. Secondly, by using the first extended symmetry, the BVP of a class of fractional differential equation with variable order is reduced to the initial value problem of ordinary differential equation system. Finally, combined with Legendre polynomial, the system of ordinary differential equation is transformed into the product of a series of matrices by differential operator matrix, and the product of matrix is transformed into algebraic equation by discrete variables. By solving the equations, the numerical solutions of the initial values of ordinary differential equations are obtained. Experiments show that the numerical solution of a class of fractional differential equations with variable 
order obtained by the proposed algorithm is of high accuracy.

\section{REFERENCES}

Baeumer, B., Geissert, M. \& Kovács, M. 2015. Existence, uniqueness and regularity for a class of semilinear stochastic Volterra equations with multiplicative noise. Journal of Differential Equations 258(2): 535-554.

Bauer, M., Escher, J. \& Kolev, B. 2015. Local and global wellposedness of the fractional order EPDiff equation on $\mathrm{R} \mathrm{d} R$ d mathContainer Loading Mathjax. Journal of Differential Equations 258(6): 2010-2053.

Bhrawy, A.H. \& Zaky, M.A. 2016. Numerical algorithm for the variable-order Caputo fractional functional differential equation. Nonlinear Dynamics 85(3): 1815-1823.

Bhrawy, A.H. \& Zaky, M.A. 2015. Numerical simulation for two-dimensional variable-order fractional nonlinear cable equation. Nonlinear Dynamics 80(1-2): 101-116.

Carrillo, J.A., Huang, Y. \& Santos, M.C. 2015. Exponential convergence towards stationary states for the 1D porous medium equation with fractional pressure. Journal of Differential Equations 258(3): 736-763.

Cozzi, M. \& Passalacqua, T. 2016. One-dimensional solutions of non-local Allen-Cahn-type equations with rough kernels. Journal of Differential Equations 260(8): 6638-6696.

Danca, M.F. 2015. Lyapunov exponents of a class of piecewise continuous systems of fractional order. Nonlinear Dynamics 81(1-2): 227-237.

El-Sayed, A.A. \& Agarwal, P. 2019. Numerical solution of multiterm variable-order fractional differential equations via shifted Legendre polynomials. Mathematical Methods in the Applied Sciences 42(2): 3978-3991.

Harko, T. \& Liang, S.D. 2016. Exact solutions of the Liénardand generalized Liénard-type ordinary nonlinear differential equations obtained by deforming the phase space coordinates of the linear harmonic oscillator. Journal of Engineering Mathematics 98(1): 93-111.

Liu, Y., Du, Y.W. \& Li, H. 2015. A two-grid finite element approximation for a nonlinear time-fractional Cable equation. Nonlinear Dynamics 85(4): 1-14.

Pan, X.L., Wang, Z.W. \& Wei, D. 2017. Nonlinear dynamic model simulation of proton exchange membrane fuel cell based on load change. Chinese Journal of Power Sources 41(2): 227-229.
Rossi, J.D. \& Topp, E. 2016. Large solutions for a class of semilinear integro-differential equations with censored jumps. Journal of Differential Equations 260(9): 6872-6899.

Shao, S.Y. \& Chen, M. 2015. Synchronization control for a class of fractional order nonlinear chaotic systems. Computer Simulation 32(4): 394-398.

Wang, D.D., Zhang, B. \& Qiu, D.Y. 2017. Phasor analysis method and study of sinusoidal steady state characteristics of the fractional-order circuits. Journal of Power Supply 15(2): 34-40

Yu, J., Wang, D.S. \& Sun, Y. 2016. Modified method of simplest equation for obtaining exact solutions of the ZakharovKuznetsov equation, the modified Zakharov-Kuznetsov equation, and their generalized forms. Nonlinear Dynamics 85(4): 2449-2465.

Zhang, W., Liu, W. \& Li, W. 2015. Independently tunable multichannel fractional-order temporal differentiator based on a silicon-photonic symmetric Mach-Zehnder interferometer incorporating cascaded microring resonators. Journal of Lightwave Technology 33(2): 361-367.

Zhang, Y., Qin, Z.C. \& Zhang, W.D. 2017. Asymmetric interference alignment for device-to-device underlaying cellular networks. Journal of China Academy of Electronics and Information Technology 12(6): 232-236.

Zúñiga-Aguilar, C.J., Romero-Ugalde, H.M. \& Gómez-Aguilar, J.F. 2017. Solving fractional differential equations of variable-order involving operators with Mittag-Leffler kernel using artificial neural networks. Chaos Solitons \& Fractals 103(2): 382-403.

The School of Mathematics and Computer Science Xinyang Vocational and Technical College

Xinyang, 464000

China

*Corresponding author; email: paneastsun@163.com

Received: 21 February 2019

Accepted: 23 December 2019 